\title{
Correction to: Structure and composition of the euglossine bee community along an elevational gradient of rupestrian grassland vegetation
}

\author{
Fabíola MENDES DOS SANTOS ${ }^{1,2}$, Wallace BEIROZ ${ }^{2,3}$, Yasmine ANTONINI ${ }^{4}$, \\ Silvana MARTÉN-RODRÍGUEZ ${ }^{5}$, Mauricio QUESADA ${ }^{5}$, \\ Geraldo Wilson FERNANDES ${ }^{2}$ \\ ${ }^{1}$ Universidade Estadual de Montes Claros, Montes Claros, Minas Gerais, Brazil \\ ${ }^{2}$ Laboratório de Ecologia Evolutiva e Biodiversidade, Departamento de Biologia Geral, Universidade Federal de Minas \\ Gerais, Belo Horizonte, Minas Gerais, Brazil \\ ${ }^{3}$ Instituto de Estudos do Xingu, Universidade Federal do Sul e Sudeste do Pará, São Félix do Xingu, Pará, Brazil \\ ${ }^{4}$ Laboratório de Biodiversidade, Departamento de Biodiversidade Evolução e Meio Ambiente, Instituto de Ciências \\ Exatas e Biológicas, Universidade Federal de Ouro Preto, Ouro Preto, Brazil \\ ${ }^{5}$ Escuela Nacional de Estudios Superiores, Unidad Morelia, Universidad Nacional Autónoma de México, Morelia, \\ Mexico
}

\section{Correction to: Apidologie https://doi.org/10.1007/s13592-020-00752-7}

Following publication of the original article, the author group noticed an error related to the presentation of Figs. 4 and 5. The author group would like readers to note that the legends of for Figs. 4 and 5 are erroneously presented and that the reverse order of what is presented in the original article was intended. This correction note stands to correct the original article.

Publisher's note Springer Nature remains neutral with regard to jurisdictional claims in published maps and institutional affiliations.

Corresponding author: Y. ANTONINI, antonini.y@gmail.com Manuscript editor: Alexandra Klein The online version of the original article can be found at https://doi.org/10.1007/s13592-020-00752-7 